\title{
Schön, dass es sie noch gibt: alte Grenzsteine im Palmengarten
}

\author{
Herbert Billensteiner
}

\section{Der Palmengarten auf „Grenzland“}

Der Palmengarten wurde 1868 auf einem ehemals N. Meyer Freiherr von Rothschild aus Wien gehörigen Grundstück am Rande der Stadt Frankfurt errichtet. Mit der allmählichen Erweiterung des Gartens nach Norden wurde auch die damalige Stadtgrenze erreicht. Der ehemalige Grenzverlauf der Freien Reichsstadt Frankfurt ist noch an drei erhaltenen Landesgrenzsteinen zu erkennen. Ein vierter Stein befindet sich am Gartenzaun an der Straßenseite zur Zeppelinallee, etwa $100 \mathrm{~m}$ rechts vom Eingang zur Villa Leonhardi. Im Botanischen

Abb. 1 (links): Der in den Zaun des Palmengartens integrierte Grenzstein.

Abb. 2 (rechts): Der Grenzstein vor dem Blütenhaus.

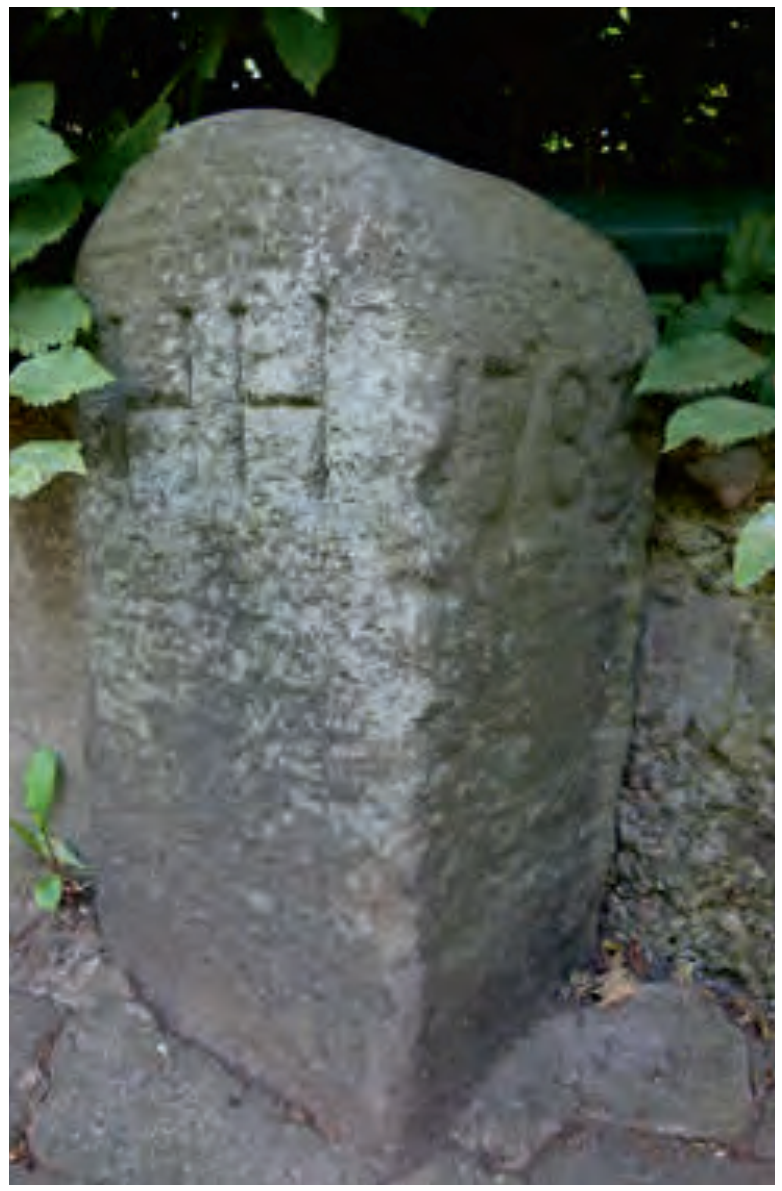

Garten sind im Eingangsbereich links und rechts des Weges zwei Grenzsteine erhalten.

\section{Erhaltene Grenzsteine}

Ein Stein mit der Nr. 119 befand sich früher an derjenigen Stelle, wo die alte Eibe im Jahr 1907 gepflanzt wurde. Dies war ein markanter Ort, weil nördlich davon früher ein „Frankfurter Stuhl“, auch „Frankfurter Ruhe“ genannt, an einer Quelle stand (vgl. Billensteiner 2013).

Einer der Steine am Rande des Spielplatzes neben der Spielwiese steht zwar noch am ursprünglichen Platz; er wurde jedoch schon einmal aus der Erde gezogen und leider verkehrt herum wieder eingesetzt. Denn nun zeigt das eingemeißelte „F“ für Freie Reichstadt Frankfurt in Richtung Bockenheim, das damals zur Grafschaft „HH“ (Hessen-Hanau) gehörte. Ein weiterer Stein steht ungefähr in der

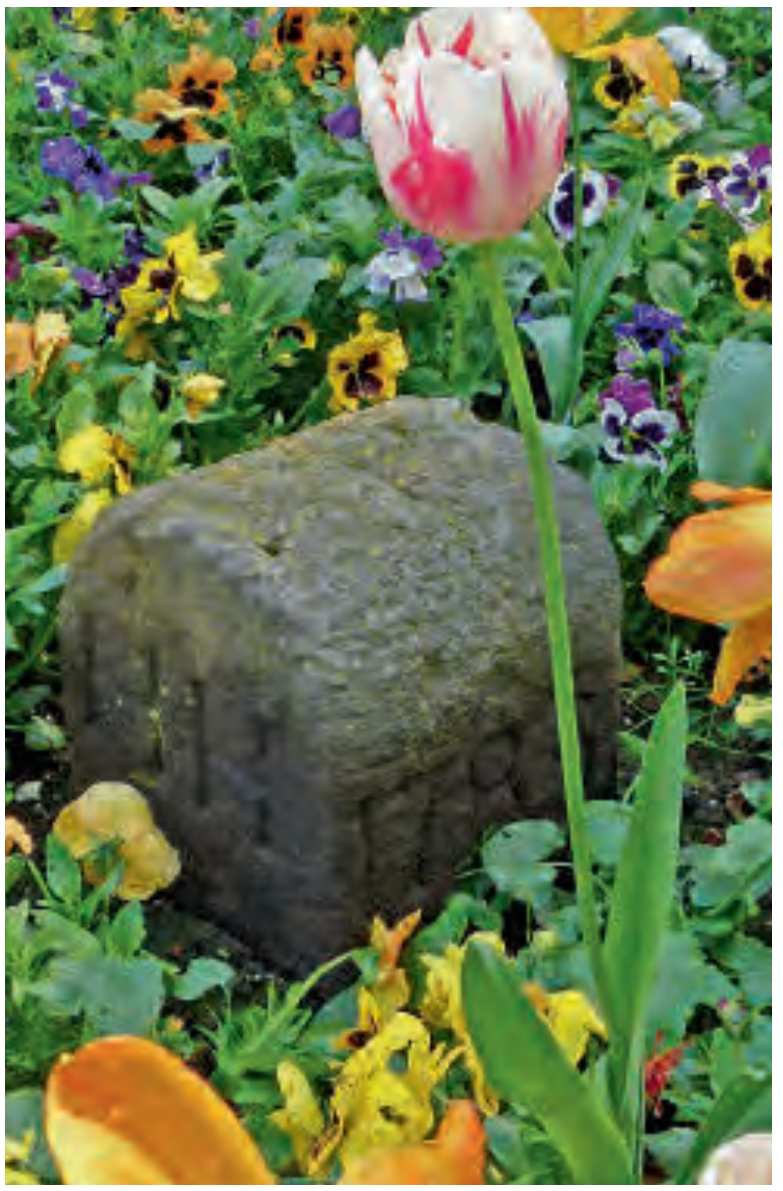



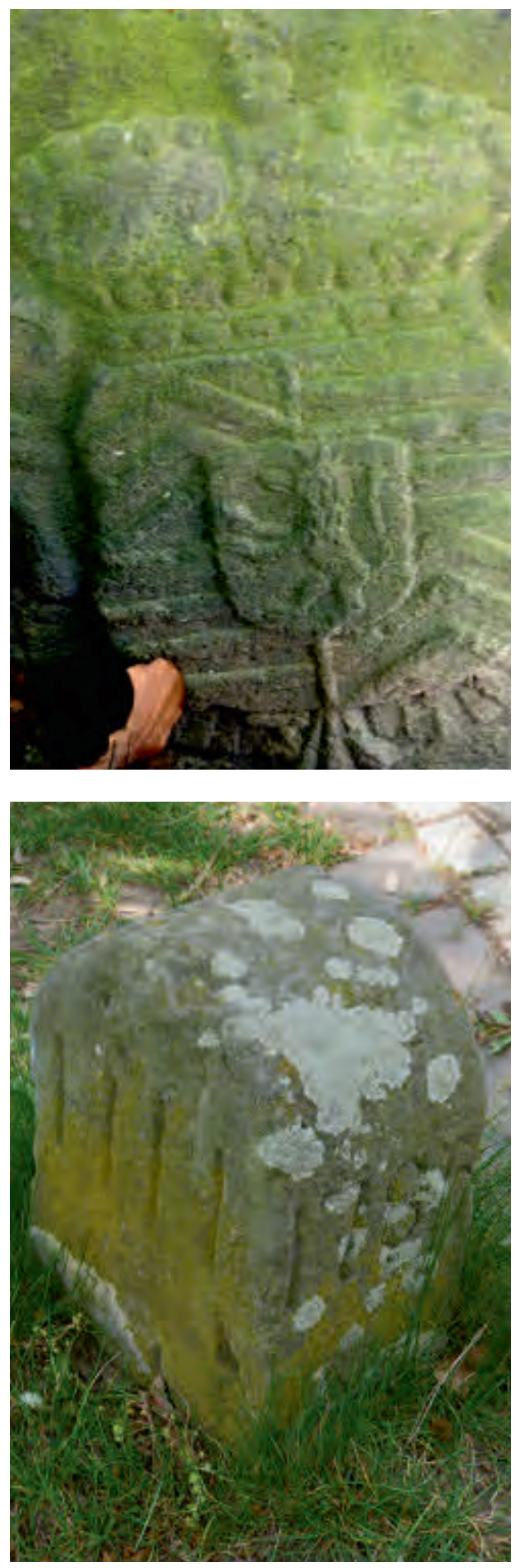

Mitte des Gartens auf der Wiese in der Nähe des Staudengartens und ist nach Westen hin ausgerichtet. Ebenfalls ein noch im Original erhaltener Stein steht vor dem Blütenhaus. Die beiden Steine im Botanischen Garten stehen im Bereich des Eingangs am Weg in der Nähe des Buchenwaldes. Vermutlich ist dies nicht ihr Originalstandort.

\section{Beschriftung der Steine}

Die Dicke der Grenzsteine beträgt ungefähr $26 \times 28 \mathrm{~cm}$, ihre Oberseite ist bogenförmig bearbeitet. Auf allen Steinen ist die Jahreszahl 1785 eingemeißelt. Mit der Entwicklung des Gemeineigentums begann man Grundeigentum abzugrenzen. Waren es anfangs Bäche, Steine oder Bäume, wurde ab dem 14. Jahrhundert die Abgrenzung von Grundstücken durch Grenzsteine üblich. Damit es nicht zu Verwechslungen kam, wurden vierkantige, glatt behauene Steine mit Inschriften oder Wappen, Ortszeichen und anderen Symbolen geschmückt. In alten Landordnungen finden sich Bestimmungen über die Steinsetzer, das Setzen, die vorzuladenden Personen, Kosten und auch Strafen für das Versetzen oder Entfernen von Grenzsteinen.

Im Rhein-Main-Gebiet war das Setzen der Grenzsteine jahreszeitlich begrenzt. Man bediente sich zum Ausmessen der Rute. Es gab dabei verschiedene Maßeinheiten: Die Frankfurter Rute war 3,56 m, die Hanauer 3,57 m, die Darmstädter 2,49 m und die Fuldaer Rute 3,39 m lang. Die Steinsetzer kennzeichneten die Steine durch geheime Unterlagen, soge-

Abb. 3 (oben): Wappen auf dem einen Grenzstein im Botanischen Garten.

Abb. 4 (unten): Flechtenbewuchs zeigt an, dass die Grenzsteine nicht mehr ganz neu sind.

Abb. 5 (Seite 71 oben): Ansicht des Steins mit der Kennzeichnung „F“ für Frankfurt.

Abb. 6 (Seite 71 unten): Der Grenzstein am Blütenhaus ist in die Sommerflorpflanzung integriert und wirkt je nach Jahreszeit ganz unterschiedlich. 
nannte Zeugen, die sie unter die Steine legten. Dies waren Kieselsteine, Topf- und Glasscherben und andere Dinge, mit deren Hilfe ein heimliches Verrücken nachvollzogen werden konnte. Wenn diese Grenzsteine reden könnten, sie würden viel erzählen über diverse Herrscher, Kriege und wechselnde Besitzer der Grundstücke.

Inzwischen gibt es Flurkarten mit eingetragenen Grenzsteinen. Die im Palmengarten und Botanischen Garten noch vorhandenen Grenzsteine sind ein Stück Geschichte der Stadt Frankfurt am Main. Heute sind sie per GPS eingemessen und in der Landeshauptstadt Wiesbaden registriert. Generell sind durch Veränderungen der Landschaft und Bebauung, aber auch durch private Sammlerleidenschaft, historische Grenzsteine stark gefährdet. Diese Kleindenkmale und steinernen Zeugen der Vergangenheit sind besonders schützenswert. Beschädigung, Entfernen oder unerlaubtes Versetzen der Grenzsteine sind strafbar.
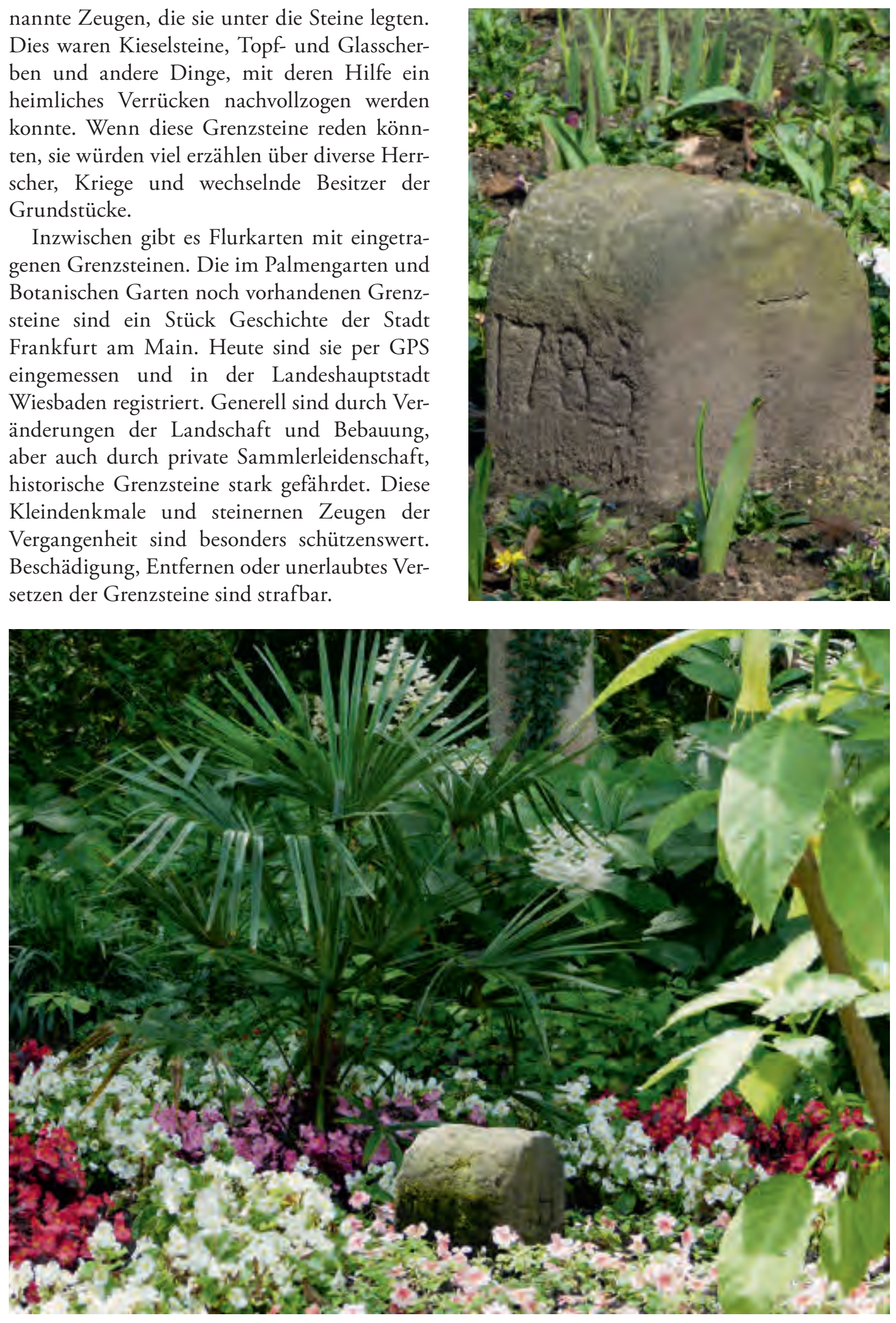